\title{
Exploring links between policy preferences for water reallocation and beliefs, values, attitudes, and social norms in Alberta, Canada
}

\author{
M. Russenberger ${ }^{1}$, H. Bjornlund ${ }^{2,3}$ \& W. Xu ${ }^{1}$ \\ ${ }^{1}$ Department of Geography, University of Lethbridge, Canada \\ ${ }^{2}$ Department of Economics, University of Lethbridge, Canada \\ ${ }^{3}$ School of Commerce, University of South Australia, Australia
}

\begin{abstract}
In many semiarid regions, total water allocations exceed levels available for extraction. Despite growing demand for water from urban and environmental uses, the majority of these allocations are held by agricultural users. In order to meet new demand in the face of uncertain future supply, water must be reallocated from irrigation to urban and environmental uses; however, such reallocation faces stiff opposition from irrigators and non-irrigators alike. Although irrigators have disproportionate power over the reallocation process, the preferences of non-irrigators with greater electoral power and contributions to tax revenue are also important to policy makers. This study explores these issues based on extensive surveys of non-irrigators in Alberta, Canada. Values, beliefs, and attitudes are found to influence policy preferences differently. Policy makers and water managers should consider these psychological constructs when designing, marketing and implementing policies and mechanisms to reallocate water in accordance with the values of wider society.
\end{abstract}

Keywords: water reallocation, values, attitudes, beliefs, rural-urban transfers.

\section{Introduction}

Around the world, growing urban populations and expanding economies are placing new and varied demands on existing freshwater resources. Growing environmental concerns have resulted in increased pressure to leave water in rivers for ecosystem health. In many arid and semiarid areas, the allocation of water resources has surpassed most estimates of what constitutes a sustainable 
level [1]. In response, some governments have stopped issuing rights to extract water and are exploring options for reducing extraction of water for consumptive use as well as facilitating water reallocation to meet new and changing demand.

Irrigated agriculture controls around $80 \%$ of allocated water in many such regions; so much of that available for reallocation will come from the irrigation sector. Reducing irrigators' access to water will necessarily decrease their productivity, profitability and property values. Such a transition will generate negative impacts on irrigators and irrigation dependent communities, as reduced farm production results in fewer jobs, declining rural populations and the loss of community services and businesses. The severity of these impacts will depend on the policies and instruments used to facilitate water reallocation.

Market-based solutions for water reallocation are widely accepted as a means of efficiently reallocating water between existing users as well as between existing and new users. In such a scenario, buyers would voluntarily compensate sellers for the losses associated with decreased access to water, while ensuring that the limited supply would move to more efficient and high value uses. The same mechanisms can also be used to secure water for in-stream flows where environmental protection is highly valued. In such cases, allocations can be purchased by the government or non-government and private organizations to be left in rivers for the environment. Despite these benefits, externalities unaccounted for in prices may accrue to the environment or other water users.

More authoritarian means of reallocation that may address these concerns could also be implemented. For example, a government could conceivably (1) withdraw an allocation held by one user and grant it to another user or the environment; or (2) determine how much water the environment needs and not allow consumptive users access to water until those needs are met. In some jurisdictions these processes could take place within current legislation, while legislative changes may be required in others. In both cases, however, the issue of whether and how to compensate previous allocation holders might be raised.

Political opposition to both means of resource reallocation exists: particularly in their most extreme forms. If necessary reallocation is to be successful, a balance must be reached between deregulated markets and government command and control, keeping in mind that public opinion of a proposed solution will have a significant impact on its political acceptability.

Although governments around the world are facing similar issues related to many natural resources, water reallocation in Southern Alberta provides an excellent case study for considering resource allocation between competing rural and urban uses and the environment. This paper discusses the findings of a survey of urban and rural non-irrigator households. The survey investigated residents' level of agreement with a variety of policy proposals related to water management in addition to a wide variety of value and attitude statements, social factors, and socio-economic indicators expected to influence policy preferences. The City of Calgary and the Town of Strathmore were chosen as case studies due to the pressing nature of the issue in these communities, and their differing social and physical proximity to irrigated agriculture. 


\section{Alberta context}

Canada has an international reputation as a resource rich nation. This perception extends to the country's freshwater resources. However, water is unevenly distributed across the country. Water is abundant in Central and Northern Canada and along the West Coast, and while the southern Prairie Provinces are relatively dry, nowhere is scarcity more of an issue than in the South Saskatchewan River Basin (SSRB) in Southern Alberta, home to some $60 \%$ of all irrigated agriculture in Canada [2].

Alberta is the westernmost of Canada's Prairie Provinces, situated just east of the continental divide. The mountains obstruct moist air coming off of the Pacific Ocean, limiting precipitation to their east. As a result the majority of the province has a dry continental climate, but benefits from a relatively steady supply of fresh water year-round as a result of the snowmelt that supplies the province's major river systems. Since precipitated water is limited, surface water is used extensively for agricultural and other uses [3].

Historically, new demand for water in Alberta has been met by allocating water rights under a prior allocation-or first-in-time, first-in-right-system. Over time, many of the sub-basins within the SSRB have been fully or over allocated, with many of the largest and most senior water licences held by the irrigation sector. Presently, 22 of 33 main rivers are suffering moderate environmental effects from water stress caused by current levels of water extraction, five more are suffering heavier environmental losses and three are classified as environmentally degraded [4]. In response, most sub-basins in the SSRB were closed to new applications for water rights in 2005. As a result, water users seeking new or expanded allocations must acquire them from existing users via transfers. Since irrigation accounts for $72 \%$ of the water allocated and $84 \%$ of that used in the SSRB [5] it is inevitable that reallocation will move water out of agriculture. The expected consequences of such reallocation vary widely: significant direct and indirect economic effects have been identified [6] and other social and environmental effects of varying significance may result [7].

Two recent occurrences in Alberta have illustrated the opposition to water trading as a mechanism for water reallocation. The first occurred in 2007, when a developer revealed plans to build a shopping centre, race track and casino at Balzac, north of Calgary. When the City of Calgary refused to supply water the developer sought to source it from the Red Deer River, where new licences were still being issued; however, the ministerial consent necessary to approve this inter-basin transfer was not obtained due to public opposition. In the end, the developer purchased a 2,500 ML allocation from the Western Irrigation District for 15 million dollars. The district then used the proceeds from the sale to line a leaking canal, thereby saving a quantity of water greater than that originally sold. Despite its appearance as a win-win scenario, the transfer raised significant opposition among irrigators (who only approved the transfer by a narrow margin), environmentalists, and other industry groups [8]. 
The second case was an attempt by the Eastern Irrigation District (EID) to amend two of its licences to allow the district to supply 940,000 ML for uses other than irrigation. Under current legislation, irrigation districts are allowed to supply water to other users (provided the new use is allowed by their licence) while maintaining ownership over the allocations themselves. This arrangement addresses the concern over losing control of their water that many irrigators expressed in the context of the Balzac transfer. Other districts have been granted the required amendments, however when the EID submitted its application it met strong opposition from the environmental sector. The argument against the amendment was that such amendments allowed the district to provide water to any user willing to pay while circumventing the environmental assessments required for the formal transfer of a water licence. The campaign to block the changes was successful and the amendment process was suspended pending further investigation by the government. The transfer was finally approved in October 2010 but is now challenged in the courts.

Both of these cases were in the spirit of the Government's water management strategy and the idea that water must be reallocated to align with society's changing needs and values is widely accepted by scholars and policymakers alike $[3,8,9]$. Nonetheless, there is still debate over how similar reallocations and amendments should take place in the future [10]. In particular, the use of markets for reallocating water is seen as problematic by some [11], a feeling which has gained significant support within the wider community $[10,12]$.

\section{Conceptual model}

Canadians overwhelmingly rank fresh water as the country's most important natural resource [13], however, the general public is neither assumed nor expected to have a strong understanding of the intricacies of water resource management upon which to base their water policy preferences [14]. Instead, individuals' decisions to support or oppose particular policies are likely to be based on psychological variables such as their values, beliefs, attitudes, and social norms $[15,16]$. If necessary water reallocation is to gain sufficiently wide acceptance to be politically feasible, we must develop an understanding of how these domains influence preferences for water management policy.

Notable research in the field of values and attitudes was undertaken by Rokeach [17], who argued that the situation-transcendent and ranked nature of values allowed for decision making in a wide variety of scenarios. This allows people to form attitudes toward value objects with which they are only minimally informed. The link between values, beliefs and attitudes was further established by other authors [18, 19], and extended to include behavioural intention and behaviour [20]. Likewise, social norms are expected to have a significant influence on policy preferences. In particular, social and physical proximity to irrigated agriculture may influence agro-environmental concern and thereby have an impact on policy choices impacting agriculture [21].

The Theory of Reasoned Action (TRA) provides a model for understanding behaviour as a function of behavioural intent, which is determined by attitudes 
and subjective norms [20]. Since end behaviours were not measured in this study, we will halt our analysis at the level of intent, understood to be the conative expression of preferences $[15,22]$. By linking the TRA to value orientations, beliefs, attitudes and social norms, we aim to better understand how individuals' water reallocation policy preferences are formed, as well as how they differ with varying social and physical distances from agriculture.

\section{Methodology}

This research is based on a mail-out survey of randomly selected households in Calgary and all available addresses in Strathmore, Alberta. The mail-out consisted of 3,000 surveys mailed to Calgary, which has a population of $1,071,515$ in 414,185 occupied dwellings [23], and 2,338 mailed to Strathmore, with its population of 12,139 in 4,483 occupied dwellings [24]. A response rate of $16.8 \%$ of the delivered surveys was achieved, with 476 responses from Calgary and 347 from Strathmore. After removing incomplete surveys and those who had self-identified as irrigators, 422 responses remained from Calgary and 302 from Strathmore. Responses were weighted by the number of household in each location so that a combined analysis for the region could be produced. Given that this is a household and not a resident survey, the respondents are not representative of the population with respect to age and gender.

The questionnaires collected information on demographics (17 items); values, attitudes and beliefs with respect to water and the environment (49 items); social factors (19 items); and policy preferences (10 items). The value, belief, attitude, policy preference and some social factor statements utilized a five-point Likert scale to measure agreement to the statements provided.

\section{Findings and discussion}

\subsection{Factor analysis}

A series of factor analyses were performed on the collected data to reduce the number of variables for analysis. Three policy orientations for water reallocation were extracted. The first factor grouped policy options requiring an increased role of government, while the second and third factors focused on policies to protect environmental and economic interests respectively. Subsequent factor analyses reduced statements making up the values, beliefs and perceptions, attitudes and social norms domains to four factors each.

The factor analysis of value variables confirmed the biospheric, egoistic and altruistic value orientations identified as contributing to environmental behaviour $[25,26]$. Respondents with a strong biospheric value orientation are more likely to identify environmental concerns as guiding factors in their lives. Those with a strong egocentric value orientation are primarily concerned with how a particular issue will affect their lives personally, while respondents scoring highly on the third and fourth factors are primarily concerned with effects on other people. Such a value orientation is frequently labelled 'altruistic'. In this study, the 
altruistic value orientation was further split into agricultural-altruistic, in which respondents stressed the importance of agriculture; and domestic-altruistic, concerned with basic human and domestic needs. In each case, a higher factor score corresponds with greater importance placed on that value construct.

The breakdown of the beliefs and perceptions domain was also consistent with that proposed in the literature. According to value-belief-norm theory [19], perceptions and beliefs mediate the impacts of values on attitudes. The first factor in the belief and perception domain consists of statements of belief that transfers will be harmful to the economy, the environment, or farmers. Those scoring highly on this factor believe transfers will be more harmful than beneficial. The second factor consists of statements related to perceptions of farmers and irrigation, which may be influenced by social or physical proximity to agriculture [21]. Respondents scoring highly on this factor see agriculture as benefiting them personally and the province in general. As a result, they may express greater concern for irrigators' rights in water reallocation. The third factor relates to knowledge and awareness of Alberta's water management framework. Respondents rating highly on this factor perceive that they have greater knowledge about the water policy context in Southern Alberta. The final factor in the beliefs and perceptions domain marries statements related to the perception that the historical water allocation system in Alberta is inadequate, including specific environmental concerns and more general concerns related to the current system being out of line with society's wider values. Respondents scoring highly on this factor perceived the need for change as more pressing. These last two factors will allow us to test the findings of Thorvaldson et al. [16] that preferences for water policy may be conditional on knowledge of water supply, scarcity and variability, and the institutions governing water rights.

While values are general constructs that transcend different situations, attitudes are situation specific evaluations about whether a particular attitude object is good or bad. The first attitude factor includes pro-environmental statements such as limiting development and industrial or agricultural expansion if it would damage the environment. Respondents scoring highly on this factor are more likely to prioritize environmental uses of water over economic uses. The second factor in the attitude domain combines items measuring respondents' level of agreement with allowing buyers and sellers to set the price of water, hence allowing price to determine who gets the right to use water. Respondents scoring highly on this factor exhibit pro-market attitudes.

Pro-use statements make up the third factor within the attitudes domain, including statements that favour productive use of water resources as opposed to leaving water in the river. Respondents who score highly on this factor are likely to feel that using water is more beneficial to themselves and society than keeping water in rivers. The final factor for the attitudes domain relates to respondents' attitudes toward government responsibility for protecting the environment and the equitable distribution of water among community members. Respondents who score highly on this factor believe the government is responsible for protecting the health of the aquatic environment in Alberta as well as people who may otherwise be unable to afford water. 
The first social norm factor measures social ties to agriculture. Incorporated into this factor are items measuring frequency of contact with farmers or farm families or having friends or family employed in agriculture or related fields. Those scoring highly on the factor may be more concerned about the impacts of water transfers on farmers and exhibit greater support for policies protecting irrigators' rights. The second factor concerns contact with rural amenities including using rural areas, rivers, lakes and reservoirs for recreation or purchasing produce from a farmers' market or farm gate. Respondents who score highly on this factor are more likely to encounter rural people and places, which may influence their preferences for rural to urban water transfers.

The third and fourth social norm factors collect items representing community cohesion and approval of water transfers. Items ranking on the social cohesion factor included those related to community agreement with respect to water policy. Respondents who score highly on this factor perceive their communities as being united with respect to water policy and environmental issues, and as such are likely to feel greater social pressure to conform their own views to those of their communities. The social approval factor reflects how the respondents perceive support for water markets within their community and among their family and friends. Respondents with high factor scores on the fourth factor feel that those around them support using markets to reallocate water.

\subsection{Linear regression analysis}

Following the factor analyses, the extracted psychological factors were used alongside location and personal and situational characteristics as independent variables in a series of multi-step regression equations for which the policy preference factors served as dependent variables. Although the effect of location was insignificant when other variables were controlled for, varying explanatory power was exhibited for all other domains, dependent on the policy orientation in question (Table 1). Notable among the psychological domains discussed in this paper, the addition of the attitude factors contributed sizably to explaining preferences for greater government control over water reallocation (adjusted Rsquare change $=0.165$ ), while more general values contributed most significantly to preferences for policy focussed on protecting the rights of the environment and irrigators (adjusted R-square change $=0.084$ and 0.140 , respectively).

Table 1: Cumulative adjusted R-squares for policy preference options.

\begin{tabular}{|c|c|c|c|}
\hline & $\begin{array}{c}\text { Government } \\
\text { power }\end{array}$ & $\begin{array}{c}\text { Improve } \\
\text { environment }\end{array}$ & $\begin{array}{c}\text { Develop } \\
\text { economy }\end{array}$ \\
\hline Location & -0.001 & -0.001 & -0.001 \\
\hline Personal Characteristics & 0.001 & 0.064 & 0.055 \\
\hline Situational Characteristics & 0.046 & 0.154 & 0.101 \\
\hline Values & 0.116 & 0.238 & 0.241 \\
\hline Beliefs and Perceptions & 0.131 & 0.247 & 0.336 \\
\hline Attitudes & 0.296 & 0.279 & 0.358 \\
\hline Social Norms & 0.301 & 0.314 & 0.366 \\
\hline
\end{tabular}




\subsubsection{Policies providing more power to the government}

Looking more closely at the determinants of policy preferences desirous of an increased role of government for determining how water should be reallocated, personal and situational characteristics and location accounted for a combined $4.6 \%$ of the variance. Within the realm of values, the egoistic value orientation and both the domestic- and agricultural-altruistic value orientations are significant predictors (Table 2). The egoistic value orientation is a relatively strong positive predictor, while both value orientations classified as altruistic show a significant but weaker negative relationship with increased government power. This distinction is indicative of the differences between concerns for ones' own consumptive needs and the needs and rights of others. This may also be interpreted as a critique of the governments' efficacy in adequately meeting the needs of various stakeholders, with the implication that if the government is to make water rights for people a priority, respondents would put first their own needs and the needs of people like them, rather than the needs of others.

Similar conclusions might be drawn based on the negative relationship between policy granting the government greater power, and the perceived inadequacy of the historic water allocation system. Because water markets are

Table 2: $\quad$ Standardized betas for psychological variables.

\begin{tabular}{|c|c|c|c|}
\hline & $\begin{array}{l}\text { Government } \\
\text { power }\end{array}$ & $\begin{array}{c}\text { Protect } \\
\text { environment }\end{array}$ & $\begin{array}{l}\text { Develop } \\
\text { economy }\end{array}$ \\
\hline \multicolumn{4}{|c|}{ Value orientations } \\
\hline Biospheric value orientation & 0.0708 & $0.1237 * * *$ & $-0.1078 * *$ \\
\hline Egoistic value orientation & $0.1667 * * *$ & 0.0140 & 0.0533 \\
\hline $\begin{array}{c}\text { Altruistic/Agricultural value } \\
\text { orientation }\end{array}$ & $-0.1494 * * *$ & 0.0325 & $0.1096 * *$ \\
\hline Altruistic/Human value orientation & $-0.0788 * *$ & -0.0591 & $-0.0821 * *$ \\
\hline \multicolumn{4}{|c|}{ Beliefs and perceptions } \\
\hline Believe transfers are harmful & 0.0139 & $0.1079 * *$ & -0.0643 \\
\hline Perceived water knowledge & 0.0190 & -0.0524 & $-0.1155^{* * *}$ \\
\hline Believe irrigation/farmers are good & 0.0730 & $0.0765^{*}$ & $0.1790 * * *$ \\
\hline $\begin{array}{l}\text { Perceived inadequacy of current } \\
\text { system }\end{array}$ & $-0.0909 *$ & -0.0044 & $-0.1451 * * *$ \\
\hline \multicolumn{4}{|c|}{ Attitudes } \\
\hline Pro-conservation attitude & $0.1898 * * *$ & $0.2165 * * *$ & $-0.1557 * * *$ \\
\hline Pro-market attitude & $-0.3706 * * *$ & $0.1080^{* *}$ & $0.1603 * * *$ \\
\hline Pro-use attitude & 0.0615 & -0.0279 & $0.1094 * *$ \\
\hline Pro-regulatory attitude & $0.2420 * * *$ & 0.0590 & 0.0368 \\
\hline \multicolumn{4}{|c|}{ Social norms } \\
\hline Social ties to agriculture & -0.0340 & $0.0789 *$ & $0.0877 * *$ \\
\hline Use of rural amenities & $-0.0958 * *$ & $0.1855^{* * *}$ & -0.0367 \\
\hline Community cohesion on water issues & 0.0654 & $0.0687^{*}$ & $0.0901 * *$ \\
\hline $\begin{array}{l}\text { Community approval of water } \\
\text { transfers }\end{array}$ & -0.0250 & $0.0756^{*}$ & -0.0234 \\
\hline
\end{tabular}

$* * * \operatorname{sig}<0.01 ; * * \operatorname{sig}<0.05 ; * \operatorname{sig}<0.1$. 
relatively new and untested in the Alberta context, the government is seen as primarily responsible for the current state of the environment. As such, those who perceive the current state of the aquatic environment as poor are unlikely to feel that the government is capable of actively managing its future demands.

The addition of attitude variable further clarifies this analysis. Specifically, respondents portraying pro-conservation and pro-regulatory attitudes were increasingly supportive of a greater governmental role in water reallocation. In both cases, the statements making up these variables dealt primarily with restricting future development that might have a negative impact on the environment, a capacity for which respondents clearly believe the government is well suited. The most influential attitude for predicting preference for greater government involvement in water reallocation, however, is the attitude that markets are not the best tool for implementing necessary reallocation.

The impact of social norms on respondents who prefer a greater government role in reallocation was minimal, with those who made more frequent use of rural amenities somewhat less in favour of a stronger government hand. This is likely a result of the fact that greater government control would move water out of rural areas, decreasing access to rural amenities.

\subsubsection{Policies focusing on protecting the environment}

Preferences for water policy focused on protecting the environment are less likely to be determined by psychological variables, as $15.4 \%$ of the variance in this policy group is determined by personal and situational characteristics. Nevertheless, values are still an important predictor of support for this policy direction. In particular, those with a biospheric value orientation are more likely to see protecting the environment as a primary concern, as would be expected.

Respondents who believe that transfers would be harmful are also more likely to favour policy focused on environmental protection. Since currently inactive licences would move naturally toward consumptive use as they are sold to higher value users, protecting the environments rights to water becomes more necessary. Encouraging environmental protection via the use of public funds to stimulate efficiency improvements among irrigators is another aspect of environmentally focused policy, and the positive relationship between such policy and the belief that irrigation and farming are beneficial implies that those in favour of environmental policy see encouraging better farming practices as suitable way of meeting environmental needs.

Like respondents who prefer greater governmental control over water reallocation, those who favour stronger environmental protection generally express pro-conservation attitudes which would limit development or economic growth that occurs at the expense of the environment. Where they differ, however, is those who make environmental policy a priority are more open to utilizing markets to achieve those goals, hence the positive link between promarket attitudes and environmental policy preferences.

Also notable is that the effect of social norms on policy preferences is greatest for those who prefer policy with an environmental emphasis. In particular, respondents who make more frequent use of rural amenities are more supportive of such policy, 
but the effect of social ties to agriculture, as well as community cohesion surrounding water issues and approval of water transfers are also significant and positive.

\subsubsection{Policies encouraging economic development and irrigator protection}

Preferences for policy encouraging economic development and the protection of irrigators' rights can also be predicted by personal and situational characteristics, however, the impact of values on preference for this policy direction is particularly strong, accounting for $14 \%$ of the variance explained in this model. Specifically, the agricultural-altruistic value orientation is positively related to this policy preference, while domestic-altruistic and biospheric value orientations are negatively linked. These relationships are consistent with the view that consumptive uses of water are most valued, and that uses that benefit the economy should take priority over concerns for the environment or equity.

Beliefs and perceptions are also strong predictors of preference for policy focused on protecting and growing economic activity such as irrigation. The perception that irrigation and agriculture are beneficial to the province as a whole was positively associated with pro-economic policy, while the perceived necessity of transfers and perceived water knowledge were negatively correlated. These relationships illustrate the acceptance of the status-quo among respondents who prefer such policies, as they are largely unaware of the pressing need for water reallocation, nor familiar with the management tools or political turmoil involved in the water reallocation debate.

As expected, respondents who prefer policies conducive to economic development also exhibit pro-use attitudes and oppose conservation at the expense of development. Notable also, is the fact that this group also holds promarket attitudes, implying that they believe water transfers facilitated by marketbased systems are a good way to reallocate water to new and expanding users.

Although social pressure are not as strong a predictor for economic focused policy as they are for environmental, social ties to agriculture and community cohesion still play a role. In both cases the relationship is positive, with preferences for protecting irrigators and encouraging economic development increasing as social ties to agriculture increase. People who feel that their communities agree on water issues are also likely to support this type of policies

\section{Conclusions}

The findings presented here provide a valuable step toward gaining a better understanding of the policy preferences of non-irrigators for water reallocation. Links between psychological variables and general environmental concern or behaviour are well-established [27], and similar links are theorized with respect to resource management preferences. By identifying the relevant factors underlying these variables with respect to water reallocation we can draw links between related branches of the literature and better inform policy to ensure its widespread acceptance and adoption.

In addition to confirming the breakdown of psychological variables explored by other authors within the context of water reallocation in Alberta, we find significant relationships between each of the three policy orientations explored 
and many of the psychological factors extracted. Preferences for greater government involvement in agriculture were most readily explained by attitudes towards specific aspects of water reallocation and use, while more general value orientations played a larger role in determining preferences for environmentaland economic-focused policies.

Another notable finding of this study with significant policy implications is that despite respondents who preferred greater government control over water reallocations' aversion to using markets to reallocate water, both those who were more environmentally focused and those who preferred economic development favoured using markets to meet the changing water needs of the province. This implies that rather than the strongly anti-market, pro-environmental contingent supposed in much of the literature surrounding water markets, a significant portion of the population is both pro-environment and pro-market.

Policy makers and water managers should consider the insight into these constructs when designing and implementing new policies and mechanisms to reallocate water to new consumptive users or the environment. These findings could also influence social marketing tools used to inform and sway public opinion about necessary water reallocation, helping to reduce social conflict and leading to more predictable policy outcomes.

\section{Acknowledgements}

Funding for this research was provided by the Alberta Water Research Institute and the Canadian Water Network

\section{References}

[1] Dyson, M., Bergkamp, G. \& Scanlon, J., Flow: The essentials of environmental flows. data.iucn.org/dbtw-wpd/edocs/2003-021.pdf, 2003.

[2] Statistics Canada, Agricultural Water Use Survey (survey no. 5145). www.statcan.gc.ca/pub/16-001-m/2009008/t008-eng.htm, 2007.

[3] Alberta Environment, Water for Life: A Renewal. Edmonton, 2008

[4] Alberta Environment, Background Information for public consultation on the SSRB's Draft Water Management Plan, Edmonton, 2005.

[5] AMEC, South Saskatchewan River Basin in Alberta: Water Supply Study, Alberta Agriculture and Rural Development, Lethbridge, 2009.

[6] Howe, C., The economic impacts of agriculture-to-urban water transfers on the area of origin: A case study of the Arkansas River Valley in Colorado. American Journal of Agricultural Economics, 72(5), 1200-1204, 1990.

[7] Gould, G., Water rights transfers and third-party effects. Land and Water Law Review, 23(1), 1-41, 1988.

[8] Bjornlund, H., The competition for water: Striking a balance among social, environmental, and economic needs. C.D. Howe Institute Commentary, 302, 1-28, 2010.

[9] Baron, J., and Coauthors, Meeting ecological and societal needs for freshwater. Ecological Applications, 12(5), 1247-1260, 2002. 
[10] Brewer, J., Glennon, R., Ker, A. \& Libecap, G., Water markets in the West: Prices, trading, and contractual forms. Economic Inquiry, 46(2), 91-112, 2008.

[11] Christensen, R. \& Droitsh, D., Fight to the last drop: A glimpse into Alberta's water future. EcoJustice Report, 1-32, 2008.

[12] Percy, D.R., Responding to water scarcity in western Canada. Texas Law Review, 83(7), 2091-2107, 2005.

[13] Nanos, N., Canadians overwhelmingly choose water as our most important natural resource. Policy Options, July-August, 12-15, 2009.

[14] Dolnicar, S., Hurlimann, A. \& Nghiem, L.D., The effect of information on public acceptance: The case of water from alternative sources. Journal of Environmental Management, 91(6), 1288-1293, 2010.

[15] Routhe, A.S., Jones, R.E. \& Feldman, D.L., Using theory to understand public support for collective actions that impact the environment: Alleviating water supply problems in a nonarid biome. Social Science Quarterly, 86(4), 874-897, 2005.

[16] Thorvaldson, J., Pritchett, J. \& Goemans, C., Western households' water knowledge, preferences, and willingness to pay. Canadian Journal of Agricultural Economics, 8(4), 497-514, 2010.

[17] Rokeach, M., Beliefs, Attitudes and Values: A Theory of Organization and Change, Jossey-Bass: San Francisco, 1968.

[18] Fishbein. M., Attitude and the prediction of behavior. Readings in Attitude Theory and Measurement, ed. M. Fishbein, Wiley: New York, 477-492, 1967.

[19] Stern, P.C., Dietz, T., Abel, T., Guagnano, G.A. \& Kalof, L., A valuebelief-norm theory of support for social movements: The case of environmentalism. Human Ecology Review, 6(2), 81-98, 1999.

[20] Fishbein, M. \& Ajzen, I., Belief, Attitude, Intention, and Behavior: An introduction to theory and research, Addison-Wesley: Ontario, 1975.

[21] Sharp, J. \& Adua, L., The social basis of agro-environmental concern: Physical versus social proximity. Rural Sociology, 74(1), 56-85, 2009.

[22] Dunlap, R. \& Jones, R., Environmental concern: Conceptual and measurement issues. Handbook of Environmental Sociology, eds. R.E. Dunlap \& W. Michelson, Greenwood Press: Westport, CN, 482-524, 2002.

[23] Calgary, City of., 2010 Civic Census Results, www.calgary.ca /docgallery/bu/cityclerks/2010_census_result_book.pdf

[24] Strathmore, Town of., 2010 Census Results, www.strathmore.ca $/ \mathrm{mod} /$ secfile/viewed.php?file_id=520

[25] Stern, P., Dietz, T. \& Kalof, L., Value orientations, gender and environmental concern. Environment and Behaviour, 25(5), 322-348, 1993.

[26] Snelgar, R.S., Egoistic, altruistic, and biospheric environmental concerns: Measurement and structure. Journal of Environmental Psychology, 26(2), 87-99, 2006.

[27] Stern P.C., Dietz, T., The value basis of environmental concern. Journal of Social Issues, 50(3), 65-84, 1994. 